\title{
IMMUNOPATHOGENESIS OF PSORIASIS AND PSORIATIC ARTHRITIS AND PHARMACOLOGICAL PERSPECTIVES
}

\author{
S. LOFFREDO ${ }^{1}$, F. AYALA ${ }^{2}$, G.C. MARONE ${ }^{1}$, A. GENOVESE ${ }^{1,3}$, G. MARONE MEN $^{1,3}$ \\ ${ }^{1}$ Division of Clinical Immunology and Allergy; \\ ${ }^{2}$ Division of Dermatology, Department of Systematic Pathology; \\ ${ }^{3}$ Center for Basic and Clinical Immunology Research (CISI), University of Naples Federico II, Naples, Italy
}

\begin{abstract}
SUMMARY
Psoriasis and psoriatic arthritis are chronic inflammatory disorders resulting from a combination of genetic and environmental factors, though the precise causal agents have not yet been identified. The immune system has a major role in their development and the possibility exists that self antigens or antigens from microbial agents, or microbial superantigens initiate a vigorous immune response. Different subsets of T-lymphocytes and dendritic cells, mast cells and granulocytes participate in the pathogenesis and several cytokines and chemokines have been identified in tissue lesions. TNF- $\alpha$ is a key proinflammatory cytokine with important pathogenetic role in psoriasis and psoriatic arthritis. Evidence from clinical trials targeting the $T N F-\alpha-T N F-\alpha-r e c e p t o r$ supports a central role for this cytokine in the pathogenesis of psoriasis and psoriatic arthritis. Angiogenesis is a prominent early event in lesional psoriatic skin and in synovial membrane psoriatic arthritis. Future potential targets in the treatment of these disorders include biologic agents aimed at blockade of other cytokines, chemokines and angiogenic factors.
\end{abstract}

Key words: Psoriasis, psoriatic arthritis, immunity

Psoriasis is an ancient inflammatory disease, first described in the Corpus Hippocraticum. Hippocrates (460-377 BCE) used the term psora, meaning "to itch". Although the etiology of the disease remains unknown, it appears to result from a combination of genetic and environmental factors. It is frequently inherited, but not following a classical autosomal mendelian profile. It is a lifelong inflammatory disease with spontaneous remissions and exacerbations. Approximately 3\% of the population worldwide is afflicted by psoriasis. Many factors trigger or exacerbate psoriasis, including bacterial pharyngitis, stress, HIV-1, and various medications (e.g., lithium and $\beta$-blockers). Although the disease is characterized by proliferation of the epidermis, the immune system has a prominent role in its development (1).

Five to $42 \%$ of patients with psoriasis have psori-

Corresponding author:

Gianni Marone, MD

Divisione di Immunologia Clinica ed Allergologia

Centro di Ricerca in Scienze Immunologiche di Base

e Cliniche (CISI)

Università di Napoli Federico II

Via Pansini 5 - 80131 Naples, Italy

E-mail:marone@unina.it atic arthritis, a disabling and occasionally destructive joint disease. The course of this form varies, with some having mild changes and others severe, rapid destruction of joints. Psoriatic arthritis is usually seronegative for rheumatoid factor and presents in several characteristic forms: oligoarticular disease, distal interphalangeal arthritis, spondylitis or sacroiliitis and arthritis mutilans (2). Cutaneous lesions precede joint disease in $60-70 \%$ of patients and the two begin simultaneously in 10-20\%. Arthritis precedes psoriasis in about $20 \%$ of patients $(2,3)$. Even when there are no skin lesions, however, nail changes can usually be found in patients with psoriatic arthritis (2).

\section{T LYMPHOCYTES AND DENDRITIC CELLS IN PSORIASIS}

In fully developed psoriatic skin lesions, there is a mixture of innate immune cells (neutrophils, mast cells, dendritic APCs and NKT cells), adaptive immune cells (both $\mathrm{CD} 4^{+}$and $\mathrm{CD} 8^{+} \mathrm{T}$ lymphocytes), and an inflammatory infiltrate (Fig. 1) $(4,5)$. There are two subsets of $\mathrm{CD}^{+} \mathrm{T}$ lymphocytes: an epidermal homing subset expressing an integrin 


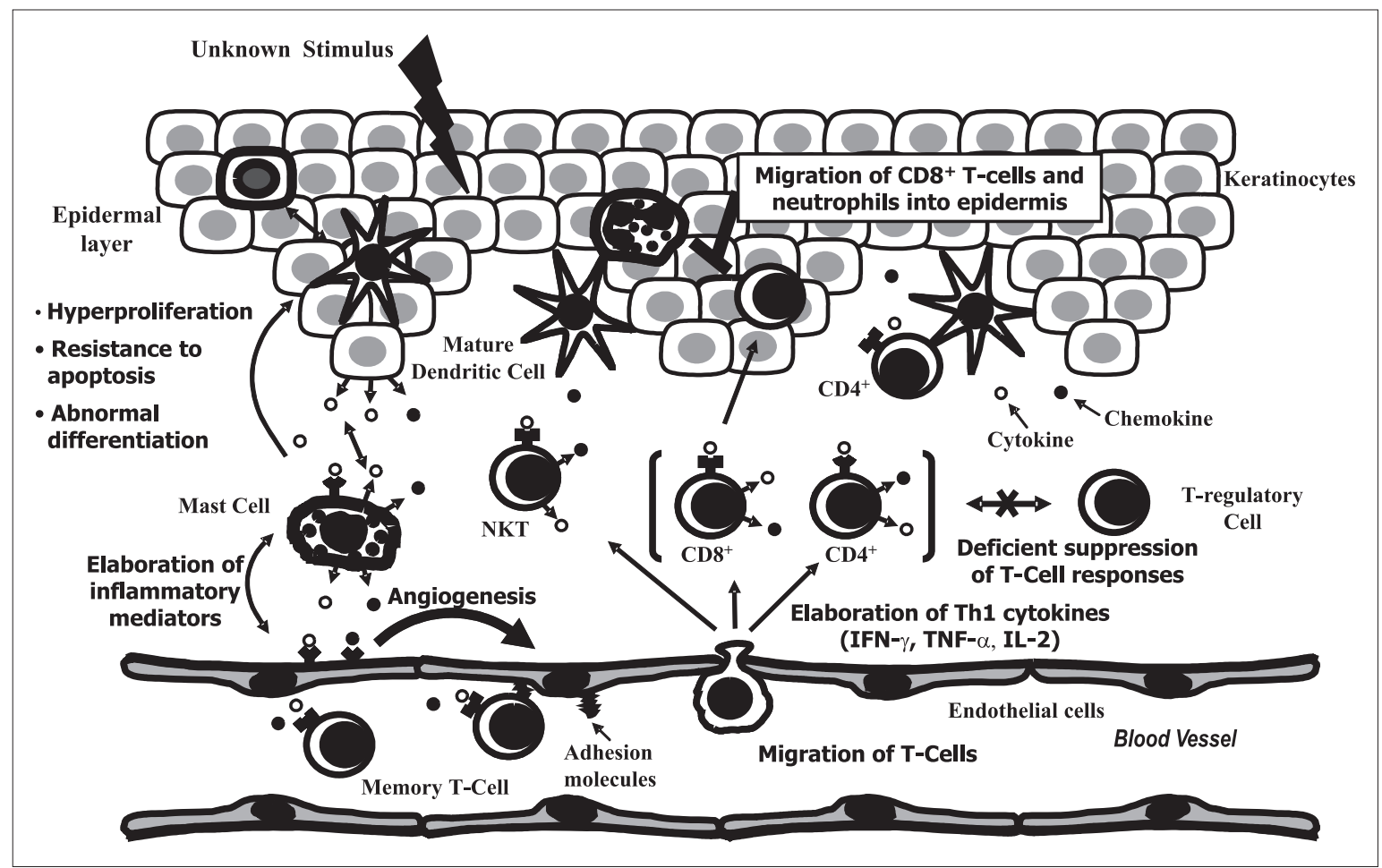

Figure 1 - Schematic representation of pathophysiology of psoriasis. The initial stimulus activating the immune system in psoriasis is not known. The development of psoriatic plaque depends on complex interactions among T-lymphocytes [CD4+ T cells, CD8+ T cells, natural killer T (NKT) cells], dendritic antigen-presenting cells (APC) such as Langerhans cells, plasmacytoid dendritic cells (DCs), mature myeloid DC subsets, neutrophils and mast cells. DC subsets cause activation of infiltrating T-cells, by cell-cell interactions the immunologic synapse being pivotal for antigen recognition. The antigen specifity of skin-infiltrating T-lymphocytes has not yet been identified. Many accessory molecules involved in the immunologic synapse (e.g., lymphocyte function-associated antigen-1, cytotoxic T-lymphocyte antigen-4) have been targeted by biologic therapies, demonstrating relevance of these pathways in psoriasis. Treg suppressor activities are deficient in skin lesions and in blood of psoriatic patients, which may permit T-cell proliferation, and chronic overproduction of Th1-derived cytokines (IFN- $\gamma$, IL-2 and TNF- $\alpha$ ) and chemokines. Therapeutic targeting of TNF- $\alpha$ with biologic agents has proved important role of this mediator of inflammation in psoriasis. Overproduction of these cytokines and growth factors causes epidermal keratinocytes to hyperproliferate and become resistant to apoptotic signals. This epidermal hyperproliferation is supported by neoangiogenesis, which is also driven by T-cell-derived inflammatory cytokines and angiogenic factors produced by mast cells and other cells.

(CD103) (6) and a subset that remains in the dermis, in transit either to or from the epidermis. Tlymphocytes in psoriatic lesions are skin-homing memory cells, HLA antigen-DR ${ }^{+}$, representing an activated state and express an $\alpha / \beta$ T- cell receptors (TCR). The epidermal CD8 ${ }^{+}$T-lymphocytes also express CD103 that enables them to interact with E-cadherin, facilitating their migration into the epidermis. Thus, the major populations of T-cells are mature, skin-homing, activated memory cells, responding to peptides presented by mature APCs. The antigen specificity of skin-infiltrating T-lymphocytes has not yet been identified. These cells may, however recognize self (epidermal- or keratinocyte-derived) polypeptides, those derived from microbial agents, or microbial superantigens (7). A classical paradigm addressing the existence of self- reactive T-lymphocytes is the molecular mimicry hypothesis, in which an immune response against a microbe elicits a vigorous immune response against epitopes cross-reacting with self-antigens (8). The link between psoriasis and certain microbial infections (i.e., streptococcal pharyngitis and guttate psoriasis) support in part this hypothesis.

Antigen recognition by T-lymphocytes requires that mature, professional APCs to process polypeptides, load them onto major histocompatibility complex class I or II molecules, and ultimately present the processed peptides to the T-cells together with a multitude of signals. This complex process requires antigen presentation in the context of the self-major histocompatibility complex (signal 1), a variety of costimulatory signals (e.g., CD86, CD80, CD40, lymphocyte function-associated antigen-3, CD54) 
for which there are receptors on the surface of $\mathrm{T}$ cells (9) (signal 2), and cytokines production by activated T-lymphocytes (signal 3). Conjugation of the T-lymphocyte and the APCs and the formation of the immunologic synapse results in complete activation of T-lymphocytes and the secretion of cytokines that are found in psoriatic lesions [interferon (IFN)- $\gamma$ and tumor necrosis factor (TNF)- $\alpha$ ].

Biologic therapies that target the immunologic synapse and, thus, interfere with T-lymphocyte activation have some efficacy in psoriasis (alefacept, efalizumab, and cytotoxic T-lymphocyte antigen4/Ig fusion protein) (10-12).

A variety of APC subtypes accumulates in psoriatic skin lesions. Myeloid dendritic cells (DCs), both immature and mature, and small numbers of plasmacytoid DCs (a source of IFN- $\alpha$ ) have been identified $(13,14)$. The presence of DC subsets whose frequency is normally very low in peripheral blood, together with activated T-cells, constitutes a fundamental aspect of the disease process, because the in situ recruitment of both cell types drives the chronic T-cell activation in the skin lesions. Antigen presentation and T-cell activation occur predominantly in peripheral lymph nodes. Thus, the identification of this network of cells within the psoriatic lesions is a fundamental aspect of how the immune system functions (or dysfunctions) in psoriasis.

\section{DEFECTIVE T-REGULATORY CELLS IN PSORIASIS}

Several subsets of T-lymphocytes have immunoregulatory functions $(15,16)$. One such subset is a $\mathrm{CD} 4^{+} \mathrm{T}$ lymphocyte that constitutively expresses CD25 (the IL-2 receptor $\alpha$ chain) and has been termed the "T-regulatory cell" $\left(\mathrm{T}_{\text {reg }}\right)$. These cells suppress immune responses and prevent the development of autoimmune diseases (17). $\mathrm{T}_{\mathrm{reg}}$ cells can suppress the activities of $\mathrm{CD}^{+}$and $\mathrm{CD} 8^{+}$ T-lymphocytes in a nonantigen-specific manner, both in vitro and in vivo, through two nonexclusive mechanisms: cell contact and suppressive cytokines such as IL-10 and transforming growth factor- $\beta$ (TGF- $\beta$ ) (18). CD $4^{+} \mathrm{CD} 25^{+} \mathrm{T}_{\text {reg }}$ cells account for approximately $10 \%$ of $\mathrm{CD} 4^{+} \mathrm{reg}$-lymphocytes in peripheral blood. Other markers of $\mathrm{T}_{\text {reg }}$ cells are expression of the transcription factor FoxP3, the co-stimulation receptor cytotoxic Tlymphocyte antigen-4 (a signaling molecule that limits T-lymphocyte proliferation), and neuropilin-
1 (NRP1) (19, 20). Interestingly, NRP1 is expressed on immune cells as a co-receptor for vascular endothelial growth factor A (VEGF-A), the most potent angiogenic factor (21).

It has been suggested that reduced $\mathrm{T}_{\text {reg }}$ cell numbers or activity might make an individual more susceptible to autoimmune diseases. $\mathrm{T}_{\text {reg }}$ cells have a role in tolerance to self-antigens, presumably protecting the host from autoimmunity. It has been recently demonstrated that mast cells are essential in inducing $\mathrm{T}_{\text {reg }}$-cell-dependent peripheral tolerance (22). Deficient $T_{\text {reg }}$ cell activity has been associated with a number of autoimmune conditions, including rheumatoid arthritis and psoriasis (2328). In patients with rheumatoid arthritis treated with the TNF- $\alpha$ antagonist infliximab, $\mathrm{T}_{\text {reg }}$ cell activity was restored (23). Sugiyama et al. demonstrated deficient $\mathrm{T}_{\mathrm{reg}}$ cell activity in the peripheral blood and in skin lesions of patients with psoriasis (26). Although the absolute number of circulating $\mathrm{T}_{\text {reg }}$ cells in patients with psoriasis was normal compared with healthy controls, they showed some deficiency in their ability to suppress effector $\mathrm{CD} 4^{+} \mathrm{T}$-lymphocyte responses. $\mathrm{T}_{\text {reg }}$ cells were also present in high numbers in skin lesions but, again were defective in their ability to suppress effector T-lymphocyte responses in skin lesions. This helps explain the defective immunoregulatory activity in psoriasis that permits T-lymphocyte activation and cytokine production. The role of $\mathrm{T}_{\mathrm{reg}}$ cell functional deficiency in psoriasis still needs clarifying.

Manipulation of $\mathrm{T}_{\text {reg }}$ cell expansion or of cytokine production by these cells could potentially provide a novel approach to the treatment of psoriasis. However, the generation of $\mathrm{T}_{\mathrm{reg}}$ cells in patients with psoriasis remains problematic in that selfantigens have not yet been identified.

\section{NKT IN PSORIASIS}

Natural Killer T-cells (NKT) are a recently recognized subset of T cells (29), distinct from NK cells in that they express a TCR, but also certain NK receptors such as CD94 and CD161. NKT cells may be double negative (expressing neither CD4 nor CD8), or they may express CD4. Another distinctive characteristic is their limited TCR repertoire, characteristically $\mathrm{V} \alpha 24 \mathrm{~J} \alpha \mathrm{Q}$ and $\mathrm{V} \beta 11$ in human beings, which limits them to recognizing only a narrow spectrum of antigens (30). This is in marked contrast to conventional $\mathrm{CD}^{+}$or $\mathrm{CD}^{+}$lympho- 
cytes, which are diverse in their TCR expression, so they recognize a broad spectrum of antigens. NKT cells recognize glycolipids ( $\alpha$-galactosylceramide or glycosylphosphatidyl inositol) presented in the context of CD1d on the APCs, rather than processed polypeptides. Glycolipids derived from sea sponges are an artificial stimulus to activate NKT-cell proliferation and cytokine production. The natural ligands for NKT cells have not been identified. Nonetheless, after activation by a glycolipid these cells proliferate and secrete cytokines such as IFN- $\gamma$, IL-4 and IL-13 and can mediate cytotoxicity. Because of this ability to secrete polarizing cytokines such as IFN- $\gamma$ (which favors Th1lymphocyte development) or IL-4/IL-13 (which favors Th2-lymphocyte development), NKT cells are thought to be important in immunoregulation of mature Th1- and Th2-lymphocyte-mediated immune responses. When NKT cells vigorously secrete IL- 2 and IFN- $\gamma$, they facilitate the development of inflammatory diseases; when they secrete predominantly IL-4 and IL-13, they tend to downregulate Th1-lymphocyte-mediated inflammatory states (29).

There have been conflicting reports as to whether NKT cells are increased in peripheral blood of patients with psoriasis $(31,32)$. NKT cells are found in the epidermis close to epidermal keratinocytes, suggesting direct antigen presentation to the former by the latter. Analysis of cultured keratinocyteNKT cell interactions indicated that IFN- $\gamma$-treated keratinocytes (mimicking cytokine-driven overexpression of CD1d as seen in psoriatic plaques), in the presence of $\alpha$-galactosylceramide, induced NKT cells to produce high levels of IFN- $\gamma$, but no detectable IL-4. This polarized cytokine pattern suggests the presence of activated Th1 lymphocytes in a psoriatic plaque. Thus, CD1d overexpressing keratinocytes contribute to the pathogenesis of the inflammatory environment by presenting endogenous glycolipids to immunoregulatory NKT cells, inducing Th1-like cytokines. The definitive role of NKT cells in the pathogenesis of psoriasis and possibly also psoriatic arthritis remains to be fully elucidated.

\section{NEUTROPHIL GRANULOCYTES IN PSORIASIS}

Early studies indicated that a primary abnormality in the lesion of psoriasis is the perivascular accumulation of neutrophils and their influx into the epidermis (33). This leads to microscopically detectable abscesses. In many patients, these micropustules may enlarge and become clinically visible as sterile $2-3 \mathrm{~mm}$ pustules. The presence of neutrophils appears to be important for the formation of psoriatic skin lesions as drug-induced agranulocytosis has been reported to result in the remission of the disease (34). Neutrophils can contribute to the hyperproliferation of keratinocytes by the effects of leukocyte elastase (35).

\section{MAST CELLS IN PSORIASIS AND PSORIATIC ARTHRITIS}

Human mast cells are usually distributed throughout normal connective tissue, where they may be found adjacent to blood and lymphatic vessels, near to or occasionally within nerves, and beneath epithelial surfaces (36). Mast cells produce a wide array of mediators and cell-cell signaling molecules, and this variety may account for the cells' unique features in the immune system (37).

Fischer et al. have reported that skin mast cell density is increased in psoriasis (38). Mast cells were the predominant $\mathrm{CD} 30$ ligand-positive $\left(\mathrm{CD} 3 \mathrm{~L}^{+}\right)$ cells in this disorder. Both CD30 and CD30L expression was upregulated in lesional skin, as was the density of $\mathrm{IL}_{-} 8^{+}$mast cells. Interestingly, engagement of CD30L on mast cells induced the release of several chemokines (IL-8, MCP-1 and MIP-1 $\alpha$ ), but not of histamine and leukotrienes. Identification of this novel pathway of mast cell activation highlights the potential role of these cells in this disorder.

Skin mast cells can be activated by other mechanisms too. Corticotropin-releasing hormone $(\mathrm{CRH})$ coordinates the systemic stress response, with repercussions on the inflammatory response (39). Psoriasis is exacerbated by stress and mast cells express $\mathrm{CRH}$ receptors and synthesize $\mathrm{CRH}$ (40). CRH also stimulates selective secretion of VEGF-A from mast cells through the activation of $\mathrm{CRH}$ receptors (41). This is an interesting link between mast cells and angiogenesis in psoriasis and psoriatic arthritis. It was been suggested that $\mathrm{CRH}$ receptor antagonists might be useful in patients with psoriasis (40).

Immunologic stimulation of human mast cells activates a specific program of gene expression leading to the de novo synthesis of a wide spectrum of cytokines (e.g., TNF- $\alpha$, SCF) $(42,43)$ and chemokines (e.g., IL-8/CXCL8, MIP-1 $\alpha /$ CCL3) 
(36). Human dermal mast cells contain and release TNF- $\alpha$ (44). In addition, mast cells of psoriatic skin are strongly positive for TNF- $\alpha$ (45) and IL-8 (38). Human skin mast cells thus appear to contribute to the local production of TNF- $\alpha$ in psoriasis and the IL-8 findings might explain the neutrophil infiltration in this disorder. Finally, mast cells in psoriatic skin are strongly positive for IFN- $\gamma$ (46), thus contributing to Th1 polarization in this disorder. Collectively, these findings provide further evidence for the important role of mast cells in the pathogenesis of psoriasis.

Mast cells are involved in the inflammatory process in various types of arthritis $(47,48)$. They can be found anywhere in the synovial membrane, but are most numerous beneath the lining layer, in the sub-intimal areas and in the capsule, frequently around synovial blood vessels (48-50). The strategic location of synovial mast cells is also supported by their close proximity to the periphery of lymphoid aggregates (51), in association with nerve endings (52), and in fibrous areas of the synovium (49-51). Synovial mast cell density is high in several forms of arthritis including psoriatic arthritis $(47,48)$. Mast cells contain and release TNF- $\alpha(42,44)$, a central mediator of psoriatic arthritis. There is compelling evidence that human mast cells express toll-like receptors (TLRs) $(53,54)$, a family of evolutionary-conserved receptors that play a role in the recognition

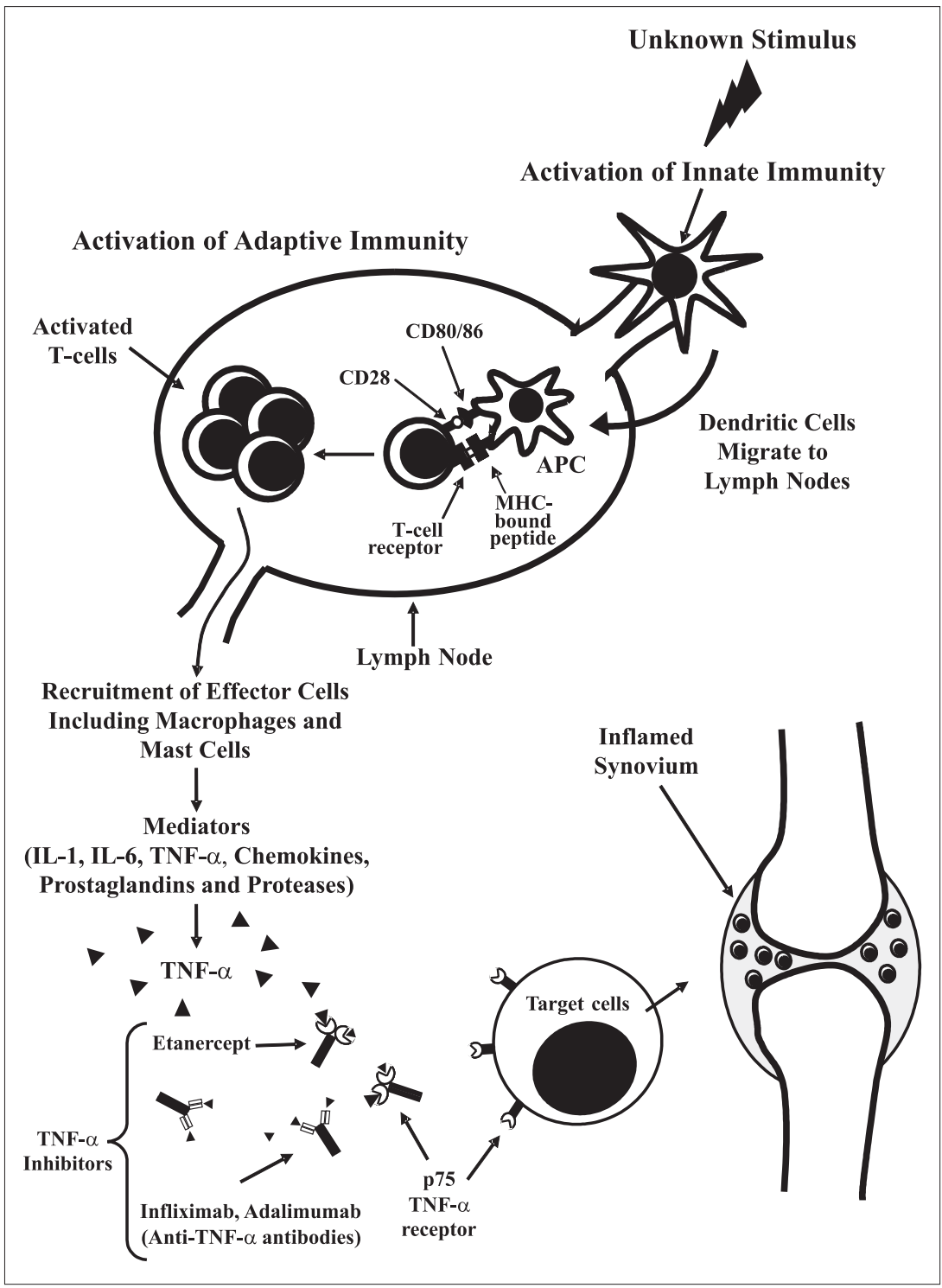

Figure 2 - Schematic representation of pathophysiology of psoriatic arthritis. An unknown stimulus binds to receptors on dendritic cells, activating the innate immune system. Dendritic cells migrate into lymph nodes, presenting antigen to T-cells, which are activated by the dual signal of antigen presentation and costimulation through CD28. Activated T-cells proliferate and migrate into the joint. In the synovial tissue, T-cells produce IFN- $\gamma$ and other proinflammatory cytokines that stimulate macrophages and fibroblasts as well as chondrocytes, osteoclasts, and B cells. Activated macrophages, fibroblasts and mast cells release a variety of cytokines, including TNF- $\alpha$. TNF- $\alpha$ is a central component in the cascade of cytokines, stimulating the production of additional inflammatory mediators and the further recruitment of immune and inflammatory cells into the joint. Therapeutic targeting of TNF$\alpha$ with monoclonal anti-TNF- $\alpha$ antibodies that bind to TNF- $\alpha$ with high affinity (infliximab and adalimumab) and prevent it binding to its receptors or a fusion protein consisting of two p75 TNF receptors linked to the Fc portion of human $\lg \mathrm{G} 1$ (etanercept) has proven important role of TNF- $\alpha$ in psoriatic arthritis. 
of foreign and self antigens (55). Expression of CRH receptors may be enhanced in psoriatic arthritis (56), and the engagement of this receptor activates mast cells (41). Finally mast cells express several isoforms of VEGF, which is the most potent angiogenic factor $(21,57)$ and angiogenesis is vital for psoriatic arthritis (57-61). These findings therefore support the idea that mast cells and their mediators play a pathogenic role in psoriatic arthritis.

\section{CYTOKINES AND CHEMOKINES IN PSORIASIS AND PSORIATIC ARTHRITIS}

The psoriatic plaque contain Th1-type cytokines (IFN- $\gamma$, IL-2, and TNF- $\alpha$ ) (62). APCs infiltrating the skin lesions also contribute to the local cytokines, which include IL-18, IL-23, and TNF- $\alpha$. IL-18 and IL-23 both induce IFN- $\gamma$ production by Th1 lymphocytes. IL-23 is a dominant cytokine in psoriatic plaques $(63,64)$ and a monoclonal antibody specific for a subunit shared by IL-12 and IL23 is effective in the treatment of psoriasis (65). NKT cells and keratinocyte-NKT cell interactions enhance the secretion of IFN- $\gamma$. The psoriasis plaque is therefore a Th1-skewed microenvironment, composed of a variety of immune cells that migrate into skin lesions: $\mathrm{CD} 4^{+}$and $\mathrm{CD} 8^{+} \mathrm{T}-1 \mathrm{ym}-$ phocytes, NKT cells, and mature DCs that secrete Th1-promoting cytokines.

Overproduction of TNF- $\alpha$ in the skin and joint has been associated with psoriasis and psoriatic arthritis (Fig. 2). The central role of TNF- $\alpha$ is confirmed by the therapeutic efficacy of TNF- $\alpha$-targeting agents (etanercept, infliximab, and adalimumab) (66-68). This cytokine is produced by macrophages, monocytes, mature DC (including Langerhans cells), polymorphonuclear cells, mast cells, NK cells, activated T-cells, keratinocytes, and endothelial cells $(44,69-73)$. High concentrations of TNF- $\alpha$ have been found in psoriatic lesions, but not in unaffected skin (74-78).

Figure 2 shows that TNF- $\alpha$ is a key proinflammatory cytokine with an important pathogenic role in psoriatic arthritis. Immunostaining of different cytokines in psoriatic arthritis synovium indicated that TNF- $\alpha$ localized both to the lining layer and to perivascular macrophages (74). The distribution of TNF- $\alpha$ expression in psoriatic arthritis is similar to that described in rheumatoid arthritis, although the extent of staining in the psoriatic form may be somewhat less as fewer macrophages in- filtrate the synovial lining. Expression of proinflammatory cytokine mRNA, including TNF- $\alpha$, was higher in the synovial tissue of patients with psoriatic arthritis than in normal synovium (79). Findings from clinical trials targeting the TNF- $\alpha-$ TNF- $\alpha$ R $(66,67)$ point to a central role for TNF$\alpha$ in the pathogenesis of psoriatic arthritis.

The relationship between local and systemic markers of inflammation, the levels of cytokines and matrix metalloproteinases (MMPs) in synovial fluid, were examined in psoriatic arthritis. Concentrations of TNF- $\alpha$, IL-1, IL-6, and IL-8 were high (78). High levels of IL-10, and MMPs were also found in the joint fluid of patients with early psoriatic arthritis (80), extending the findings of a previous study that reported increased production of these cytokines in cell cultures from psoriatic arthritis joints (78). A variety of other cytokines are increased in psoriatic lesions such as IL-15, which promotes $\mathrm{CD} 8^{+} \mathrm{T}$-lymphocyte expansion, keratinocyte hyperplasia and resistance to apoptosis (81).

Several chemokines (IL8/CXCL8, TARC/CCL17, MIG/CXCL19, IP-10/CXCL10, MDC/CCL22, RANTES/CCL5, MIP-3 $\alpha / C C L 20$ and MIP$3 \beta /$ CCL19) and chemokine receptors (CXCR2, CXCR3, CCR4, CCL27-CCR10, and CCR6) found in psoriatic plaques are highly relevant to the pathogenesis of psoriasis, because they promote the migration of bone marrow-derived cells into psoriatic lesions $(82,83)$.

\section{TOLL-LIKE RECEPTORS IN PSORIASIS}

Toll-like receptors (TLRs) are a family of cell-surface receptors that are key components of the innate immune response (55). The innate immune system rapidly responds to microbial products and orchestrates the appropriate cellular response to defend the host. For this to occur, a foreign organism must be quickly recognized and identified as a threat. Thus far, ten TLRs have been identified in human beings. When a specific TLR is engaged by a microbial ligand, a signaling cascade is set in motion to generate a protective inflammatory response. Considering the role of TLRs in the innate immune response and in triggering inflammation, it has been suggested that they may be involved in the psoriasis, in the recognition of exogenous, microbial products or either of self-ligands such as fibronectin or heat shock protein (HSP) (55). 
TLR1 and TLR2 expression was increased in psoriatic keratinocytes, whereas TLR5 was down-regulated compared with normal human skin (84). Monomethylfumarate, a compound used to treat psoriasis, inhibited the DC response to LPS with a dramatic decrease in IL-12 and IL-10 production (85). Another study compared TLR and HSP expression in normal and psoriatic skin. HSPs are naturally occurring ligands that engage TLR4 (86). They are overexpressed by keratinocytes in psoriatic lesions and it has been suggested they might serve as an autoantigen for $\mathrm{T}$ cells that migrate into psoriatic lesions. This same study found that TLR1 was expressed in normal skin and psoriatic plaques by epidermal and dermal DCs, TLR2 was expressed by dermal DCs, and TLR4 was expressed by epidermal and dermal DCs, with epidermal keratinocytes expressing TLR4. In vitro treatment of DC cultures with HSP increased the production of IL-12, suggesting that keratinocytederived HSP may play a role in the maturation and cytokine secretion by DCs in psoriatic lesions. HSPs may serve as triggers for both innate immunity (by TLR4 activation and maturation of APCs with the production of inflammatory cytokines) and adaptive immunity (autoreactive $\mathrm{T}$ cells specific for HSP).

The A domain of fibronectin is another endogenous ligand that can activate TLR4 (87). This domain is present at the basement membrane of uninvolved skin of patients with psoriasis, but not in the skin of healthy controls (88). The A domain of fibronectin can trigger TLR4 in Langerhans cells, raising the intriguing possibility that keratinocytederived A domain of fibronectin play a role in Langerhans cell maturation, and cytokine (TNF- $\alpha$ and IL-12) secretion. This event can promote antigen presentation to Th1 lymphocytes that migrate into psoriatic plaques. In addition, the TLR7/8 agonist imiquimod applied topically to psoriasis lesions can aggravate them (89). Lastly, single stranded messenger RNA from HIV-1 and other viruses activates TRL7 (90) and HIV-1 infection can exacerbate psoriasis (91). Thus, TLR7/8 signaling may be involved in psoriatic exacerbations by naturally occurring or synthetic ligands of these TLRs. In conclusion, evidence is emerging that TLRs may be involved in the pathophysiology of certain aspects of psoriasis. Further studies are needed to clarify their contribution to the inflammatory processes in psoriasis and in psoriatic arthritis and to investigate whether specific TRL antagonists are of any use in these disorders.

\section{ANGIOGENESIS IN PSORIASIS AND PSORIATIC ARTHRITIS}

The formation of new blood vessels (angiogenesis) is vital for numerous inflammatory and immune disorders including psoriasis and psoriatic arthritis (92). Several growth factors play important roles in angiogenesis. VEGF is the most potent proangiogenetic factor (93). Psoriatic lesions contain growth factors such as VEGF, transforming growth factor- $\alpha$ (TGF- $\alpha$ ), insulin-like growth factor-1 (IGF-1) and nerve growth factor (NGF). These contribute to epidermal hyperplasia, angiogenesis, resistance to apoptosis, and T-lymphocyte activation. Cutaneous blood vessels show major abnormalities in psoriatic lesions (94). There is compelling evidence that VEGF expression is increased in lesional psoriatic skin, that the serum levels of VEGF are elevated in patients with severe disease, and that VEGF levels are related with disease activity $(58-61,95)$. Young et al provided evidence, based on the analysis of polymorphisms of the VEGF gene in psoriatic and healthy individuals, that an "angiogenetic constitution" might determine psoriasis susceptibility (96). A role of VEGF in the pathogenesis of psoriasis was further supported by the phenotype of transgenic mice with overexpression of VEGF. These mice had enhanced skin vascularity and vascular permeability (97) and spontaneously developed chronic inflammatory skin lesions that histologically closely resemble human psoriasis (98). These changes included epidermal hyperplasia, up-regulation of adhesion molecules, accumulation of $\mathrm{CD}^{+}{ }^{+} \mathrm{T}-\mathrm{lym}-$ phocytes within the dermis and of $\mathrm{CD} 8^{+}$cells within the epidermis. Moreover, VEGF transgenic mice showed the characteristic Koebner phenomenon, with induction of chronic psoriasis-like lesions by unspecific skin irritation (98).

Angiopoietins are the major ligands of the endothelial receptor Tie 2. Angiopoietin 1 (Ang-1) induces Tie 2 signaling and maintains vessel formation, while angiopoietin 2 (Ang-2) destabilizes vessels by blocking Tie 2 signaling as an antagonist of angiopoietin 1 and acts with VEGF to initiate angiogenesis (99). Ang-1 and 2 and Tie 2 expression is upregulated in perivascular regions in lesional psoriatic skin $(100,101)$.

Angiogenesis is also a prominent early event in synovial membrane psoriatic arthritis $(102,103)$. VEGF and TGF- $\beta$ levels are elevated in the joint fluid in early psoriatic arthritis (104) and expression of angiopoietins colocalise with VEGF in 
perivascular areas of the psoriatic arthritis synovial membrane. (102). Mast cells, which are closely associated with blood vessels and increase at angiogenic sites, can contribute to various aspects of angiogenesis $(105,106)$. Mast cells synthesize and release various proangiogenic factors (histamine, tryptase, TGF- $\beta$, IL- 8 , VEGF, and I309/CCL1) (107-109). The expression of VEGF and its receptors and their functional interactions in human basophils and mast cells has been recently explored. Mast cells and basophils constitutively express several isoforms of VEGF-A $\left(\right.$ VEGF-A ${ }_{121}$, VEGF-A ${ }_{165}$ and VEGF-A ${ }_{189}$ ) and their immunologic and non immunologic activation induces the release of VEGF-A. VEGF-A is chemotactic for mast cells and basophils presumably through interaction with VEGF receptors and coreceptors (NRP1 and NRP2) present on these cells $(21,57)$.

The urokinase plasminogen activator (uPA) and its high-affinity receptor (UPAR) are involved in tissue remodeling and vessel sprouting (92). The uPA receptor (uPAR) is expressed by human basophils (110) and by mast cells (111). It thus appears that mast cells and basophils might contribute to angiogenesis in psoriasis and psoriatic arthritis.

\section{CONCLUSIONS AND PERSPECTIVES}

Psoriasis and psoriatic arthritis are complex diseases that rely on immune-mediated inflammation to sustain epidermal hyperproliferation and joint damage, respectively. In both conditions an intricate network of different cell types interacts to induce chronic inflammation. Advances in immunology, cell biology, and molecular biology have given valuable details about the immune cells, effector molecules, and signaling pathways involved in these processes.

Advances in understanding the immunopathogenesis of psoriasis and psoriatic arthritis have led to worthwhile improvements in treatment. Targeting the TNF- $\alpha /$ TNF- $\alpha$ R system clearly benefits the majority of patients with psoriatic skin lesions, but they can also improve the inflammatory process in psoriatic joints. However, we still lack a real cure for these common and enigmatic diseases, and we have not identified the genes or antigens responsible. Given the remarkable success of several different agents that target TNF- $\alpha$ in psoriasis and psoriatic arthritis, it is likely that further agents aimed at other cytokines or chemokines will surface in the near future. However, not all of these biological drugs work equally well in all patient groups, nor does the same drug necessarily improve both skin and joint manifestations equally. Also, since these drugs require injections for systemic delivery, local and systemic reactions can occur.

Potential targets in the treatment of psoriasis and psoriatic arthritis include T-cell trafficking, T-cell activation and cytokine/chemokine antagonists. Future challenges include careful monitor of patients receiving new biologics and investigating the longterm sequelae of chronic inflammatory inhibitors as regards potential risks of infections and neoplasms. In addition, we must carry on working to define the cytokine and chemokine networks operative both upstream and downstream from TNF- $\alpha$. Then we need to identify the specific triggers that explain the initial production of cytokines and chemokines. Finally, it will be important to elucidate the genetic basis by which these heterogeneous diseases are transmitted from generation to generation.

Perhaps lessons learned from research into the immunopathogenesis and treatment of these complex disorders will also pay dividends for patients with other cytokine-mediated chronic inflammatory autoimmune diseases too, including rheumatoid arthritis, lupus erythematosus, and inflammatory bowel disorders.

\section{Acknowledgments}

The authors apologize for omitting numerous important references because of space constraints. This work was supported in part by grants from the Istituto Superiore Sanità (AIDS Project 40.G.38), Ministero dell'Università e della Ricerca (MUR), Ministero della Salute (Alzheimer Project) (Rome, Italy) and Regione Campania (Naples, Italy).

\section{REFERENCES}

1. Gladman DD, Brockbank J. Psoriatic arthritis. Expert Opin Investig Drugs 2000; 9: 1511-22.

2. Scarpa R, Oriente P, Pucino A, Torella M, Vignone L, Riccio A, et al. Psoriatic arthritis in psoriatic patients. Br J Rheumatol 1984; 23: 246-50.

3. Biondi Oriente C, Scarpa R, Pucino A, Oriente P. Psoriasis and psoriatic arthritis. Dermatological and rheumatological co-operative clinical report. Acta Derm Venereol Suppl (Stockh) 1989; 146: 69-71.

4. Griffiths CE. The immunological basis of psoriasis. J Eur Acad Dermatol Venereol 2003; 17: 1-5.

5. Prinz JC. The role of T cells in psoriasis. J Eur Acad Dermatol Venereol 2003; 17: 257-70. 
6. Pauls K, Schon M, Kubitza RC, Homey B, Wiesenborn A, Lehmann P, et al. Role of integrin alpha $\mathrm{E}$ (CD103) beta7 for tissue-specific epidermal localization of CD8+ T lymphocytes. J Invest Dermatol 2001; 117: 569-75.

7. Gaspari AA. Innate and adaptive immunity and the pathophysiology of psoriasis. J Am Acad Dermatol 2006; 54: S67-80.

8. Christen U, von Herrath MG. Induction, acceleration or prevention of autoimmunity by molecular mimicry. Mol Immunol 2004; 40: 1113-20.

9. Carreno BM, Collins M. The B7 family of ligands and its receptors: new pathways for costimulation and inhibition of immune responses. Annu Rev Immunol 2002; 20: 29-53.

10. Abrams JR, Lebwohl MG, Guzzo CA, Jegasothy BV, Goldfarb MT, Goffe BS, et al. CTLA4Ig-mediated blockade of T-cell costimulation in patients with psoriasis vulgaris. J Clin Invest 1999; 103: 1243-52.

11. Ellis CN, Krueger GG. Treatment of chronic plaque psoriasis by selective targeting of memory effector $\mathrm{T}$ lymphocytes. N Engl J Med 2001; 345: 248-55.

12. Lebwohl M, Sherer D, Washenik K, Krueger GG, Menter A, Koo J, et al. A randomized, double-blind, placebo-controlled study of clobetasol propionate $0.05 \%$ foam in the treatment of nonscalp psoriasis. Int J Dermatol 2002; 41: 269-74.

13. Deguchi M, Aiba S, Ohtani H, Nagura H, Tagami H. Comparison of the distribution and numbers of antigen-presenting cells among T-lymphocyte-mediated dermatoses: $\mathrm{CD}_{1}{ }^{+}$, factor XIIIa ${ }^{+}$, and $\mathrm{CD}^{+} 8^{+}$cells in eczematous dermatitis, psoriasis, lichen planus and graft-versus-host disease. Arch Dermatol Res 2002; 294: 297-302.

14. McGregor JM, Barker JN, Ross EL, MacDonald DM. Epidermal dendritic cells in psoriasis possess a phenotype associated with antigen presentation: in situ expression of beta 2-integrins. J Am Acad Dermatol 1992; 27: 383-8.

15. Umetsu DT, Akbari O, Dekruyff RH. Regulatory T cells control the development of allergic disease and asthma. J Allergy Clin Immunol 2003; 112: 480-7.

16. Wraith DC, Nicolson KS, Whitley NT. Regulatory $\mathrm{CD}^{+} \mathrm{T}$ cells and the control of autoimmune disease. Curr Opin Immunol 2004; 16: 695-701.

17. Olivares-Villagomez D, Wensky AK, Wang Y, Lafaille JJ. Repertoire requirements of $\mathrm{CD}^{+} \mathrm{T}$ cells that prevent spontaneous autoimmune encephalomyelitis. J Immunol 2000; 164: 5499-507.

18. Waldmann H. Immunology: protection and privilege. Nature 2006; 442: 987-8.

19. Bruder D, Probst-Kepper M, Westendorf AM, Geffers R, Beissert S, Loser K, et al. Neuropilin-1: a surface marker of regulatory T cells. Eur J Immunol 2004; 34 : 623-30.

20. Fontenot JD, Gavin MA, Rudensky AY. Foxp3 programs the development and function of $\mathrm{CD} 4^{+} \mathrm{CD} 25^{+}$ regulatory T cells. Nat Immunol 2003; 4: 330-6.

21. de Paulis A, Prevete N, Fiorentino I, Rossi FW, Staibano S, Montuori N, et al. Expression and func- tions of the vascular endothelial growth factors and their receptors in human basophils. J. Immunology 2006; 177: 7322 .

22. Lu LF, Lind EF, Gondek DC, Bennett KA, Gleeson MW, Pino-Lagos K, et al. Mast cells are essential intermediaries in regulatory T-cell tolerance. Nature 2006; 442: 997-1002.

23. Ehrenstein MR, Evans JG, Singh A, Moore S, Warnes $\mathrm{G}$, Isenberg DA, et al. Compromised function of regulatory $\mathrm{T}$ cells in rheumatoid arthritis and reversal by anti-TNFalpha therapy. J Exp Med 2004; 200: 27785.

24. Kriegel MA, Lohmann T, Gabler C, Blank N, Kalden JR, Lorenz HM. Defective suppressor function of human $\mathrm{CD} 4^{+} \mathrm{CD} 25^{+}$regulatory $\mathrm{T}$ cells in autoimmune polyglandular syndrome type II. J Exp Med 2004; 199: 1285-91.

25. Ou LS, Goleva E, Hall C, Leung DY. T regulatory cells in atopic dermatitis and subversion of their activity by superantigens. J Allergy Clin Immunol 2004; 113: 756-63.

26. Sugiyama H, Gyulai R, Toichi E, Garaczi E, Shimada S, Stevens SR, et al. Dysfunctional blood and target tissue $\mathrm{CD} 4{ }^{+} \mathrm{CD} 25^{\text {high }}$ regulatory $\mathrm{T}$ cells in psoriasis: mechanism underlying unrestrained pathogenic effector T cell proliferation. J Immunol 2005; 174 : 164-73.

27. Veldman C, Hohne A, Dieckmann D, Schuler G, Hertl M. Type I regulatory $\mathrm{T}$ cells specific for desmoglein 3 are more frequently detected in healthy individuals than in patients with pemphigus vulgaris. J Immunol 2004; 172: 6468-75.

28. Viglietta V, Baecher-Allan C, Weiner HL, Hafler DA. Loss of functional suppression by $\mathrm{CD} 4{ }^{+} \mathrm{CD} 25^{+}$regulatory T cells in patients with multiple sclerosis. J Exp Med 2004; 199: 971-9.

29. Kay AB. Natural killer T cells and asthma. N Engl J Med 2006; 354: 1186-8.

30. van der Vliet HJ, Molling JW, von Blomberg BM, Nishi N, Kolgen W, van den Eertwegh AJ, et al. The immunoregulatory role of CD1d-restricted natural killer T cells in disease. Clin Immunol 2004; 112: 8-23.

31. Cameron AL, Kirby B, Griffiths CE. Circulating natural killer cells in psoriasis. Br J Dermatol 2003; 149: 160-4.

32. Chen A, Lum R, Criswell L, Russell R. Men with early rheumatoid arthritis are more likely to respond to treatment with etanercept than women; older women are more likely to respond to methotrexate than older man. Arthritis Rheum 2003; 48: s130.

33. Jablonska S. Immunological mechanisms in psoriasis: role of polymorphonuclear leukocytes. Psoriasis 1986; 131-7.

34. Toichi E, Tachibana T, Furukawa F. Rapid improvement of psoriasis vulgaris during drug-induced agranulocytosis. J Am Acad Dermatol 2000; 43: 391-5.

35. Rogalski C, Meyer-Hoffert U, Proksch E, Wiedow O. Human leukocyte elastase induces keratinocyte proliferation in vitro and in vivo. J Invest Dermatol 2002; 118: 49-54. 
36. Marone G, Triggiani M, Genovese A, de Paulis A. Role of human mast cells and basophils in bronchial asthma. Adv Immunol 2005; 88: 97-160.

37. Marone G, Triggiani M, de Paulis A. Mast cells and basophils: friends as well as foes in bronchial asthma? Trends Immunol 2005; 26: 25-31.

38. Fischer M, Harvima IT, Carvalho RF, Moller C, Naukkarinen A, Enblad G, et al. Mast cell CD30 ligand is upregulated in cutaneous inflammation and mediates degranulation-independent chemokine secretion. J Clin Invest 2006; 116: 2748-56.

39. O'Kane M, Murphy EP, Kirby B. The role of corticotropin-releasing hormone in immune-mediated cutaneous inflammatory disease. Exp Dermatol 2006; 15143-53.

40. Theoharides TC, Donelan JM, Papadopoulou N, Cao J, Kempuraj D, Conti P. Mast cells as targets of corticotropin-releasing factor and related peptides. Trends Pharmacol Sci 2004; 25: 563-8.

41. Cao J, Papadopoulou N, Kempuraj D, Boucher WS, Sugimoto K, Cetrulo CL, et al. Human mast cells express corticotropin-releasing hormone $(\mathrm{CRH})$ receptors and CRH leads to selective secretion of vascular endothelial growth factor. J Immunol 2005; 174 : 7665-75.

42. Gordon JR, Galli SJ. Mast cells as a source of both preformed and immunologically inducible TNF-alpha/cachectin. Nature 1990; 346: 274-6.

43. Patella V, Giuliano A, Bouvet JP, Marone G. Endogenous superallergen protein Fv induces IL-4 secretion from human FceRI' cells through interaction with the VH3 region of IgE. J Immunol 1998; 161: 5647-55.

44. Walsh LJ, Trinchieri G, Waldorf HA, Whitaker D, Murphy GF. Human dermal mast cells contain and release tumor necrosis factor alpha, which induces endothelial leukocyte adhesion molecule 1. Proc Natl Acad Sci U S A 1991; 88: 4220-4.

45. Ackermann L, Harvima IT. Mast cells of psoriatic and atopic dermatitis skin are positive for TNF-alpha and their degranulation is associated with expression of ICAM-1 in the epidermis. Arch Dermatol Res 1998; 290: 353-9.

46. Ackermann L, Harvima IT, Pelkonen J, Ritamaki-Salo V, Naukkarinen A, Harvima RJ, et al. Mast cells in psoriatic skin are strongly positive for interferon-gamma. Br J Dermatol 1999; 140: 624-33.

47. de Paulis A, Ciccarelli A, Marino I, de Crescenzo G, Marino D, Marone G. Human synovial mast cells. II. Heterogeneity of the pharmacologic effects of antiinflammatory and immunosuppressive drugs. Arthritis Rheum 1997; 40: 469-78.

48. de Paulis A, Marino I, Ciccarelli A, de Crescenzo G, Concardi M, Verga L, et al. Human synovial mast cells. I. Ultrastructural in situ and in vitro immunologic characterization. Arthritis Rheum 1996; 39: 1222-33.

49. Crisp AJ, Chapman CM, Kirkham SE, Schiller AL, Krane SM. Articular mastocytosis in rheumatoid arthritis. Arthritis Rheum 1984; 27845-51.
50. Gruber B, Poznansky M, Boss E, Partin J, Gorevic P, Kaplan AP. Characterization and functional studies of rheumatoid synovial mast cells. Activation by secretagogues, anti-IgE, and a histamine-releasing lymphokine. Arthritis Rheum 1986; 29: 944-55.

51. Pereira da Silva JA, Carmo-Fonseca M. Peptide containing nerves in human synovium: immunohistochemical evidence for decreased innervation in rheumatoid arthritis. J Rheumatol 1990; 17: 1592-9.

52. Wynne-Roberts CR, Anderson CH, Turano AM, Baron M. Light- and electron-microscopic findings of juvenile rheumatoid arthritis synovium: comparison with normal juvenile synovium. Semin Arthritis Rheum 1978; 7: 287-302.

53. Kulka M, Metcalfe DD. TLR3 activation inhibits human mast cell attachment to fibronectin and vitronectin. Mol Immunol 2006; 43: 1579-86.

54. McCurdy JD, Olynych TJ, Maher LH, Marshall JS. Cutting edge: distinct Toll-like receptor 2 activators selectively induce different classes of mediator production from human mast cells. J Immunol 2003; 170: 1625-9.

55. Kang SS, Kauls LS, Gaspari AA. Toll-like receptors: applications to dermatologic disease. J Am Acad Dermatol 2006; 54: 951-83.

56. McEvoy AN, Bresnihan B, FitzGerald O, Murphy EP. Corticotropin-releasing hormone signaling in synovial tissue from patients with early inflammatory arthritis is mediated by the type 1 alpha corticotropin-releasing hormone receptor. Arthritis Rheum 2001; 44: 1761-7.

57. Marone G, Prevete N, Fiorentino I, Staibano S, Rossi FW, Leone CA, et al. Vascular endothelial growth factor-A is stored in and immunologically released from human basophils. XXVI Symposium del Collegium Internationale Allergologicum 2007; in press:

58. Bhushan M, McLaughlin B, Weiss JB, Griffiths CE. Levels of endothelial cell stimulating angiogenesis factor and vascular endothelial growth factor are elevated in psoriasis. Br J Dermatol 1999; 141: 1054-60.

59. Creamer D, Allen MH, Groves RW, Barker JN. Circulating vascular permeability factor/vascular endothelial growth factor in erythroderma. Lancet 1996; 348: 1101.

60. Detmar M, Brown LF, Claffey KP, Yeo KT, Kocher $\mathrm{O}$, Jackman RW, et al. Overexpression of vascular permeability factor/vascular endothelial growth factor and its receptors in psoriasis. J Exp Med 1994; 180: 1141-6.

61. Nielsen HJ, Christensen IJ, Svendsen MN, Hansen U, Werther K, Brunner N, et al. Elevated plasma levels of vascular endothelial growth factor and plasminogen activator inhibitor-1 decrease during improvement of psoriasis. Inflamm Res 2002; 51: 5637.

62. Austin LM, Ozawa M, Kikuchi T, Walters IB, Krueger JG. The majority of epidermal T cells in Psoriasis vulgaris lesions can produce type 1 cytokines, interferongamma, interleukin-2, and tumor necrosis factor-alpha, defining TC1 (cytotoxic T lymphocyte) and TH1 
effector populations: a type 1 differentiation bias is also measured in circulating blood T cells in psoriatic patients. J Invest Dermatol 1999; 113: 752-9.

63. Chan JR, Blumenschein W, Murphy E, Diveu C, Wiekowski M, Abbondanzo S, et al. IL-23 stimulates epidermal hyperplasia via TNF and IL-20R2-dependent mechanisms with implications for psoriasis pathogenesis. J Exp Med 2006; 203: 2577-87.

64. Lee E, Trepicchio WL, Oestreicher JL, Pittman D, Wang F, Chamian F, et al. Increased expression of interleukin 23 p19 and p40 in lesional skin of patients with psoriasis vulgaris. J Exp Med 2004; 199: 125-30.

65. Kauffman CL, Aria N, Toichi E, McCormick TS, Cooper KD, Gottlieb AB, et al. A phase I study evaluating the safety, pharmacokinetics, and clinical response of a human IL-12 p40 antibody in subjects with plaque psoriasis. J Invest Dermatol 2004; 123 : 1037-44.

66. Gordon KB, Ruderman EM. The treatment of psoriasis and psoriatic arthritis: an interdisciplinary approach. J Am Acad Dermatol 2006; 54: S85-91.

67. Mease PJ, Antoni CE. Psoriatic arthritis treatment: biological response modifiers. Ann Rheum Dis 2005; 64 Suppl 2: ii78-82.

68. Weinberg JM, Bottino CJ, Lindholm J, Buchholz R. Biologic therapy for psoriasis: an update on the tumor necrosis factor inhibitors infliximab, etanercept, and adalimumab, and the T-cell-targeted therapies efalizumab and alefacept. J Drugs Dermatol 2005; 454455.

69. Beutler B, Cerami A. Tumor necrosis, cachexia, shock, and inflammation: a common mediator. Annu Rev Biochem 1988; 57: 505-18.

70. Gordon JR, Galli SJ. Release of both preformed and newly synthesized tumor necrosis factor alpha (TNFalpha)/cachectin by mouse mast cells stimulated via the Fc epsilon RI. A mechanism for the sustained action of mast cell-derived TNF-alpha during IgE-dependent biological responses. J Exp Med 1991; 174:103-7.

71. Kimber I, Cumberbatch M, Dearman RJ, Bhushan M, Griffiths CE. Cytokines and chemokines in the initiation and regulation of epidermal Langerhans cell mobilization. Br J Dermatol 2000; 142: 401-12.

72. Moss ML, Jin SL, Becherer JD, Bickett DM, Burkhart W, Chen WJ, et al. Structural features and biochemical properties of TNF-alpha converting enzyme (TACE). J Neuroimmunol 1997; 72: 127-9.

73. Vassalli P. The pathophysiology of tumor necrosis factors. Annu Rev Immunol 1992; 10: 411-52.

74. Danning CL, Illei GG, Hitchon C, Greer MR, Boumpas DT, McInnes IB. Macrophage-derived cytokine and nuclear factor kappaB p65 expression in synovial membrane and skin of patients with psoriatic arthritis. Arthritis Rheum 2000; 43: 1244-56.

75. Ettehadi P, Greaves MW, Wallach D, Aderka D, Camp RD. Elevated tumor necrosis factor-alpha (TNF-alpha) biological activity in psoriatic skin lesions. Clin Exp Immunol 1994; 96: 146-51.

76. Nickoloff BJ, Karabin GD, Barker JN, Griffiths CE,
Sarma V, Mitra RS, et al. Cellular localization of interleukin-8 and its inducer, tumor necrosis factor-alpha in psoriasis. Am J Pathol 1991; 138: 129-40.

77. Partsch G, Steiner G, Leeb BF, Dunky A, Broll H, Smolen JS. Highly increased levels of tumor necrosis factor-alpha and other proinflammatory cytokines in psoriatic arthritis synovial fluid. J Rheumatol 1997; 24: 518-23.

78. Ritchlin C, Haas-Smith SA, Hicks D, Cappuccio J, Osterland CK, Looney RJ. Patterns of cytokine production in psoriatic synovium. J Rheumatol 1998; 25: 1544-52.

79. Kane D, FitzGerald O. Tumor necrosis factor-alpha in psoriasis and psoriatic arthritis: a clinical, genetic, and histopathologic perspective. Curr Rheumatol Rep 2004; 6: 292-8.

80. Fraser A, Fearon U, Billinghurst RC, Ionescu M, Reece R, Barwick T, et al. Turnover of type II collagen and aggrecan in cartilage matrix at the onset of inflammatory arthritis in humans: relationship to mediators of systemic and local inflammation. Arthritis Rheum 2003; 48: 3085-95.

81. Ruckert R, Asadullah K, Seifert M, Budagian VM, Arnold R, Trombotto C, et al. Inhibition of keratinocyte apoptosis by IL-15: a new parameter in the pathogenesis of psoriasis? J Immunol 2000; 165: 2240-50.

82. Krueger JG. The immunologic basis for the treatment of psoriasis with new biologic agents. J Am Acad Dermatol 2002; 46: 1-23.

83. Nickoloff BJ, Nestle FO. Recent insights into the immunopathogenesis of psoriasis provide new therapeutic opportunities. J Clin Invest 2004; 113: 166475.

84. Baker BS, Ovigne JM, Powles AV, Corcoran S, Fry L. Normal keratinocytes express Toll-like receptors (TLRs) 1, 2 and 5: modulation of TLR expression in chronic plaque psoriasis. Br J Dermatol 2003; 148: 670-9.

85. Litjens NH, Rademaker M, Ravensbergen B, Rea D, van der Plas MJ, Thio B, et al. Monomethylfumarate affects polarization of monocyte-derived dendritic cells resulting in down-regulated Th1 lymphocyte responses. Eur J Immunol 2004; 34: 565-75.

86. Curry JL, Qin JZ, Bonish B, Carrick R, Bacon P, Panella $J$, et al. Innate immune-related receptors in normal and psoriatic skin. Arch Pathol Lab Med 2003; 127: 178-86.

87. Okamura Y, Watari M, Jerud ES, Young DW, Ishizaka ST, Rose J, et al. The extra domain A of fibronectin activates Toll-like receptor 4. J Biol Chem 2001; 276: 10229-33.

88. Ting KM, Rothaupt D, McCormick TS, Hammerberg C, Chen G, Gilliam AC, et al. Overexpression of the oncofetal Fn variant containing the EDA splice-in segment in the dermal-epidermal junction of psoriatic uninvolved skin. J Invest Dermatol 2000; 114: 706-11.

89. Gilliet M, Conrad C, Geiges M, Cozzio A, Thurlimann W, Burg G, et al. Psoriasis triggered by toll-like receptor 7 agonist imiquimod in the presence of der- 
mal plasmacytoid dendritic cell precursors. Arch Dermatol 2004; 140: 1490-5.

90. Heil F, Hemmi H, Hochrein H, Ampenberger F, Kirschning C, Akira S, et al. Species-specific recognition of single-stranded RNA via toll-like receptor 7 and 8. Science 2004; 303: 1526-9.

91. Diebold SS, Kaisho T, Hemmi H, Akira S, Reis e Sousa C. Innate antiviral responses by means of TLR7-mediated recognition of single-stranded RNA. Science 2004; 303: 1529-31.

92. Carmeliet P. Angiogenesis in health and disease. Nat. Med. 2003; 9: 653-60.

93. Nagy JA, Dvorak AM, Dvorak HF. VEGF-A ${ }^{(164 / 165)}$ and PlGF: roles in angiogenesis and arteriogenesis. Trends Cardiovasc. Med. 2003; 13: 169-75.

94. Braverman IM, Sibley J. Role of the microcirculation in the treatment and pathogenesis of psoriasis. J Invest Dermatol 1982; 78: 12-7.

95. Creamer D, Allen M, Jaggar R, Stevens R, Bicknell R, Barker J. Mediation of systemic vascular hyperpermeability in severe psoriasis by circulating vascular endothelial growth factor. Arch Dermatol 2002; 138791-6.

96. Young HS, Summers AM, Bhushan M, Brenchley PE, Griffiths CE. Single-nucleotide polymorphisms of vascular endothelial growth factor in psoriasis of early onset. J Invest Dermatol 2004; 122: 209-15.

97. Detmar M, Brown LF, Schon MP, Elicker BM, Velasco P, Richard L, et al. Increased microvascular density and enhanced leukocyte rolling and adhesion in the skin of VEGF transgenic mice. J Invest Dermatol 1998; 1111-6.

98. Xia YP, Li B, Hylton D, Detmar M, Yancopoulos GD, Rudge JS. Transgenic delivery of VEGF to mouse skin leads to an inflammatory condition resembling human psoriasis. Blood 2003; 102: 161-8.

99. Yancopoulos GD, Davis S, Gale NW, Rudge JS, Wiegand SJ, Holash J. Vascular-specific growth factors and blood vessel formation. Nature 2000; 407: 242-8.

100. Kuroda K, Sapadin A, Shoji T, Fleischmajer R, Lebwohl M. Altered expression of angiopoietins and Tie2 endothelium receptor in psoriasis. J Invest Dermatol 2001; 116: 713-20.

101. Markhan T, Fearon U, Mullan R. Anti-TNF alpha therapy in psoriasis: clinical and angiogenic responses. Br J Dermatol 2003; 143: 40.
102. Fearon U, Griosios K, Fraser A, Reece R, Emery P, Jones PF, et al. Angiopoietins, growth factors, and vascular morphology in early arthritis. J Rheumatol 2003; 30: 260-8.

103. Reece RJ, Canete JD, Parsons WJ, Emery P, Veale DJ. Distinct vascular patterns of early synovitis in psoriatic, reactive, and rheumatoid arthritis. Arthritis Rheum 1999; 42:1481-4.

104. Fearon U, Reece R, Smith J, Emery P, Veale DJ. Synovial cytokine and growth factor regulation of MMPs/TIMPs: implications for erosions and angiogenesis in early rheumatoid and psoriatic arthritis patients. Ann N Y Acad Sci 1999; 878: 619-21.

105. Hiromatsu Y, Toda S. Mast cells and angiogenesis. Microsc Res Tech 2003; 60: 64-9.

106. Ribatti D, Polimeno G, Vacca A, Marzullo A, Crivellato E, Nico B, et al. Correlation of bone marrow angiogenesis and mast cells with tryptase activity in myelodysplastic syndromes. Leukemia 2002; 16 : 1680-4.

107. Boesiger J, Tsai M, Maurer M, Yamaguchi M, Brown LF, Claffey KP, et al. Mast cells can secrete vascular permeability factor/vascular endothelial cell growth factor and exhibit enhanced release after immunoglobulin E-dependent upregulation of FceRI expression. J Exp Med 1998; 188: 1135-45.

108. Gilchrest H, Cheewatrakoolpong B, Billah M, Egan RW, Anthes JC, Greenfeder S. Human cord blood-derived mast cells synthesize and release I-309 in response to IgE. Life Sci 2003; 73: 2571-81.

109. Grutzkau A, Kruger-Krasagakes S, Baumeister H, Schwarz C, Kogel H, Welker P, et al. Synthesis, storage, and release of vascular endothelial growth factor/vascular permeability factor (VEGF/VPF) by human mast cells: implications for the biological significance of VEGF206. Mol Biol Cell 1998; 9: 875-84.

110. de Paulis A, Montuori N, Prevete N, Fiorentino I, Rossi FW, Visconte V, et al. Urokinase induces basophil chemotaxis through a urokinase receptor epitope that is an endogenous ligand for formyl peptide receptor-like 1 and -like 2. J Immunol 2004; 173 : 5739-48.

111. Sillaber C, Baghestanian M, Hofbauer R, Virgolini I, Bankl HC, Fureder W, et al. Molecular and functional characterization of the urokinase receptor on human mast cells. J. Biol. Chem. 1997; 272: 7824-32. 